\title{
A percepção de homens trans sobre a relação entre voz e expressão de gênero em suas interações sociais.
}

\author{
The perception of trans men about the relationship \\ between voice and gender expression in their social \\ interactions.
}

\section{La percepción de hombres trans sobre la relación entre voz y expresión de género en sus interacciones sociales.}

Alana Dantas Barros ${ }^{1}$

Edu Turte Cavadinha ${ }^{2}$

Ana Valéria Machado Mendonça ${ }^{3}$

RESUMO: Introdução: A comunicação - verbal e não verbal - é um aspecto importante do comportamento humano e da expressão de gênero. Sendo a voz um fator marcante na percepção de gênero, a não conformidade entre estes elementos pode gerar sentimentos de inadequação e um potencial impacto psicossocial mesmo sobre a voz e a própria comunicação, na expressão de gênero de homens trans. O objetivo do presente trabalho foi de analisar a percepção dos homens trans sobre expressão de gênero e interações sociais, influenciadas pela voz e pela comunicação. Método: Pesquisa qualitativa de base teórico-filosófica na hermenêutica dialética, orientada pela noção de performatividade de gênero. Foram realizadas entrevistas semiestruturadas por uma fonoaudióloga, com sete homens trans de várias regiões do Brasil, com idades entre 18 e 42 anos. Resultados e Discussão: A análise das entrevistas possibilitou o surgimento de categorias analíticas relacionadas à voz e à comunicação nas interações sociais, envolvendo o suporte de profissional da voz na saúde coletiva. As categorias foram interpretadas de maneira integrada ao contexto social e de saúde estudado. Conclusão: A compreensão da perspectiva dos homens trans sobre voz e comunicação possibilita o desenvolvimento de abordagens de cuidado culturalmente competentes, sem padrões normativos de gênero, com respeito às individualidades e às variadas maneiras de

\footnotetext{
1 Fonoaudióloga, Mestranda em Saúde Coletiva, Departamento de Saúde Coletiva, Universidade de Brasília.

2 Doutor em Saúde Pública, professor voluntário Departamento de Saúde Coletiva, Universidade de Brasília.

3 Doutora em Ciência da Informação, professora adjunta Departamento de Saúde Coletiva, Universidade de Brasília.
} 
expressão de gênero, em especial, para a saúde coletiva, buscando equidade e integralidade em saúde, e oferecendo subsídios para que a fonoaudiologia possa contribuir para a autoestima e a saúde dos homens trans.

Palavras-chave: Pessoas Transgêneras, Homem Transexual, Homem Trans, Identidade de Gênero, Voz, Qualidade da Voz, Saúde Coletiva, Fonoaudiologia.

\begin{abstract}
Introduction: Communication - verbal and non-verbal - is an important aspect of human behavior and expression of gender. Since voice is a significant factor in gender perception, non-conformity between these elements can generate feelings of inadequacy and a potential psychosocial impact even on voice and communication itself, in the gender expression of trans men. The objective of this study was to analyze the perception of trans men about gender expression and social interactions, influenced by voice and communication. Method: Qualitative research of theoretical-philosophical basis in dialectical hermeneutics, guided by the notion of gender performativity. Semi-structured interviews were conducted by a speech therapist, with seven trans men from different regions of Brazil, aged between 18 and 42 years. Results and Discussion: The analysis of the interviews allowed the emergence of analytical categories related to voice and communication in social interactions, involving voice professional support in collective health. The categories were interpreted in an integrated manner to the social and health context studied. Conclusion: Understanding the perspective of transgender men on voice and communication enables the development of culturally competent care approaches, without normative gender norms, with respect to individualities and the various ways of expressing gender, especially, for collective health, seeking equity and integrality in health, and offering subsidies so that the speech therapist can contribute to the self-esteem and health of trans men.
\end{abstract}

Key words: Transgender Persons, Transmasculine, Female-to-Male Transgender, FtM, Gender Identity, Voice, Voice Quality, Public Health, Speech Therapy.

RESUMEN: Introducción: La comunicación, verbal y no verbal, como un aspecto importante del comportamiento humano y la expresión de género. Siendo la voz un factor marcante en la percepción de género, la no conformidad de la voz con la expresión del mismo, puede generar sentimientos de inadecuación, teniendo un potencial impacto psicosocial sobre voz y comunicación en la expresión de género de hombres trans. Con el objetivo de analizar la percepción de los hombres sobre la expresión de género e interacciones sociales, influenciadas por la voz y la comunicación. Método: Investigación cualitativa de base teórico filosófica en la hermenéutica dialéctica, orientada por la noción de performatividad de género. En la que se realizaron entrevistas semiestructuradas por una fonoaudióloga con siete hombres trans de varias regiones de Brasil con edades entre 18 y 42 años. Resultados y Discusión: El análisis de las entrevistas posibilitó el surgimiento de categorías analíticas relacionadas a la voz y comunicación en las interacciones sociales, involucrando las relaciones entre voz, salud e interacciones sociales y el soporte de profesional de la voz en la salud colectiva. Las categorías fueron interpretadas de manera integrada al contexto social y de salud estudiado. Conclusión: Comprender la perspectiva de los hombres sobre voz y comunicación, 
posibilita el desarrollo de enfoques de cuidado culturalmente competentes, sin patrones normativos de género, con comprensión y respeto a las individualidades y variadas maneras de expresión de género. En especial para la salud colectiva buscando equidad e integralidad en salud, ofreciendo subsidios para que la fonoaudiología pueda contribuir a la autoestima y salud de los hombres trans. Palabras clave: Personas Transgénero, Hombres Transexuales, Identidad de Género, Voz, Calidad de la Voz, Entrenamiento de la Voz, Salud Pública, Fonoaudiología.

\section{INTRODUÇÃO}

A Política Nacional de Saúde Integral de Lésbicas, Gays, Bissexuais, Travestis e Transexuais (PNSI-LGBT), que objetiva promover a saúde integral de tal grupo, buscando a eliminação de discriminações e a redução das desigualdades na atenção à saúde, considera a discriminação por identidade de gênero, o preconceito e o estigma social como determinantes sociais da saúde ${ }^{1}$.

Uma iniciativa importante quanto à saúde da população LGBT corresponde ao atendimento das demandas de pessoas transexuais ${ }^{2}$, as quais, neste trabalho, serão tratadas de acordo com a seguinte abordagem: "A expressão de características de gênero, incluindo identidades, que não são estereotipicamente associadas com o sexo atribuído ao nascimento, é um fenômeno humano comum culturalmente diverso, que não deve ser julgado como inerentemente patológico ou negativo"3.

Nessa perspectiva, como referência internacional à saúde integral das pessoas transexuais, a World Professional Association for Transgender Health (WPATH) tem se dedicado à construção de padrões de cuidado integral, dentre os quais traz a comunicação - verbal e não verbal - como um aspecto importante do comportamento humano e expressão de gênero. Assim, as pessoas transexuais e com variabilidade de gênero, que desejem ou sintam tal necessidade, podem desenvolver características vocais e padrões de comunicação não verbal que propiciem conforto à sua identidade de gênero. Para tanto, é essencial que os profissionais da área compreendam as questões relacionadas à identidade de gênero, como os objetivos quanto à expressão do papel de gênero e as preocupações apresentadas por essas pessoas, respeitando e sendo sensíveis às preferências individuais de comunicação ${ }^{3,4}$.

Sendo a voz um fator marcante na percepção do gênero, a não conformidade entre estes elementos pode gerar sentimentos de inadequação, tendo um potencial impacto psicossocial ${ }^{5-8}$. Em decorrência disto, as pessoas transexuais podem experimentar várias formas de angústia referentes a como se sentem em relação ao seu gênero, ou sobre como seu gênero é lido socialmente, além de outros fatores psicossociais não específicos de gênero 9 .

Inicialmente, o foco das mudanças relacionadas à voz estava em elevar a frequência fundamental desta, no caso das mulheres transexuais, e abaixar sua frequência fundamental, no caso dos homens trans. No entanto, a ressonância do trato vocal, a respiração e a entonação da fala também

ISSN 1982-8829 Tempus, actas de saúde colet, Brasília, 11(4), 09-24, dez, 2017. Epub Ago/2018 
contribuem para a percepção do gênero, uma vez que estas características apresentam diferenças entre mulheres e homens ${ }^{10,11}$.

A reflexão quanto à interação entre voz e gênero pode ser vinculada a uma questão muito presente na vida social de algumas pessoas trans, chamada "passabilidade", a qual, entre diferentes sentidos, pode remeter ao fato de a pessoa ser lida socialmente de acordo o gênero com o qual se identifica, e está associada não somente ao conforto e à segurança sociais, como também à expressão de gênero. Esta compatibilidade com os estereótipos de gênero em vigor socialmente é considerada como algo fundamental para grande parte das pessoas trans, uma vez que o fato de serem socialmente passáveis pode influenciar desde a satisfação pessoal de serem reconhecidas como realmente são até situações como sua segurança em relação a ações transfóbicas ${ }^{12}$.

No Brasil, são escassos os estudos relacionados à população transexual, especificamente sobre os homens trans, sendo fundamental que se desenvolvam para o mapeamento, a análise e o entendimento da saúde integral das pessoas trans no País ${ }^{12}$. Mesmo a literatura internacional sobre função vocal, exclusivamente abrangendo homens trans, ainda é limitada, tanto em número quanto em qualidade científica ${ }^{13}$. Esta escassez pode estar ligada à crença científica de que os homens trans não teriam problemas vocais ou necessidade de atenção relacionada à voz pelo fato de que o tratamento hormonal com testosterona levaria a uma transformação satisfatória de suas estruturas de produção vocal e, consequentemente, da sua voz. Ou pode ocorrer pelo fato de este ser um grupo heterogêneo, cujos membros podem não compartilhar o mesmo tipo de corpo, identidade de gênero ou desejo de abordagens em saúde para a transição de gênero ${ }^{9,13,14}$.

Apesar da limitação da literatura, já há evidências de restrições vocais com as quais os homens trans convivem, mas ainda muito focadas nos aspectos anatômico e fisiológico, como o tratamento hormonal $^{13,15}$. Deste modo, são necessárias mais investigações sobre os diferentes fatores que afetam as situações vocais dos homens trans, para além destes aspectos, que levem em consideração a diversidade desta população, sua situação psicossocial e práticas que possam estar associadas à adequação da função vocal. E que possam trazer à luz aspectos relacionados ao que se tem como barreiras de comunicação e aos elementos que podem ser identificados enquanto facilitadores, no sentido de fatores ou práticas que expandam ou potencializem a função vocal dos homens trans, visando transpor tais obstáculos ${ }^{15}$.

Considerando o exposto, justifica-se a busca por compreender a influência das situações vocais no processo saúde-doença-cuidado da população citada, visando à reflexão e ao intento de uma prática efetiva na promoção da saúde integral das pessoas transexuais.

\section{METODOLOGIA}

Trata-se de uma pesquisa de abordagem qualitativa, desenvolvida sob a perspectiva da Teoria Queer apoiada nas contribuições de Judith Butler sobre performatividade de gênero ${ }^{16}$. Buscou-se, no 
método da hermenêutica dialética ${ }^{17}$, as bases teórico-filosóficas para o desenvolvimento da pesquisa, assim como a análise, interpretação e compreensão dos discursos dos atores envolvidos, na escuta qualificada obtida por meio de entrevistas semiestruturadas, realizadas por uma fonoaudióloga.

A fim de abranger a diversidade regional e cultural do País, as entrevistas ocorreram em seis cidades, de cinco estados de cada uma das regiões brasileiras. A composição do grupo de participantes do estudo se deu através da técnica de bola de neve ${ }^{18}$, a qual utiliza cadeias de referências, útil para estudar determinados grupos difíceis de serem acessados ${ }^{19}$. Quando visto de forma crítica, este método de amostragem popular pode gerar um precioso tipo de conhecimento social - conhecimento emergente, político e interacional ${ }^{18}$.

Por meio de tal metodologia, os participantes foram indicados e convidados por pessoas que já conheciam a pesquisa ou a pesquisadora. Após a indicação dos prováveis participantes, pelos informantes-chave, a pesquisadora realizou contato telefônico ou via mídias sociais (Facebook e WhatsApp). No primeiro contato, foram-lhes transmitidas informações a respeito da pesquisadora, do tipo de abordagem teórica e profissional, dos objetivos da pesquisa e do formato da entrevista.

Os critérios de inclusão foram: pessoas maiores de 18 anos que se identificassem como transexuais, fosse como homens trans ou com uma expressão de gênero masculina. Não houve critérios de exclusão.

Para compreender como se dá a percepção dos homens trans sobre sua voz e comunicação em suas interações sociais, foram realizadas entrevistas abertas semiestruturadas, gravadas e posteriormente transcritas. Além disso, foi desenvolvido um diário de campo, contemplando experiências e observações incorporadas às discussões do estudo.

O presente trabalho faz parte de uma pesquisa de mestrado em Saúde Coletiva do Programa de Pós-Graduação em Saúde Coletiva da Universidade de Brasília (UnB), aprovada pelo Comitê de Ética em Pesquisa da Faculdade de Ciências da Saúde da UnB, sob o número 51975315.4.0000.0030. O Termo de Consentimento Livre e Esclarecido foi assinado pela pesquisadora responsável e pelos participantes que aceitaram colaborar com o estudo.

\section{RESULTADOS E DISCUSSÃO}

Participaram sete homens trans, com idades entre 18 e 42 anos, de diferentes cidades do Brasil (no Distrito Federal e nos estados do Acre, Ceará, Paraná e São Paulo), representando as cinco regiões brasileiras.

Das pessoas que aceitaram participar e marcaram encontros presenciais para a entrevista, apenas duas não compareceram. Durante os encontros, as entrevistas semiestruturadas foram aprofundadas à medida que o diálogo se fortalecia entre a pesquisadora e os entrevistados, o que promoveu o comprometimento com os questionamentos durante a sessão de escuta.

ISSN 1982-8829 Tempus, actas de saúde colet, Brasília, 11(4), 09-24, dez, 2017. Epub Ago/2018 
Vale ressaltar, aqui, a resistência relatada por um dos informantes-chave que indicavam possíveis participantes. Algumas pessoas apresentaram resistência e/ou se recusaram a participar da pesquisa devido a experiências desconfortáveis em pesquisas anteriores ou com algum tipo de atendimento inadequado que receberam de profissionais de saúde em eventos anteriores. E esse ponto oportunizou uma reflexão acerca da necessidade de adequação das abordagens em saúde ${ }^{4,7}$, assim como de pesquisas científicas envolvendo populações vulneráveis. Devido ao fato de a sociedade brasileira ainda apresentar-se pouco familiarizada com a temática da diversidade de gênero, as pessoas trans, ao serem atendidas em um serviço de saúde ou participarem de pesquisas científicas, podem sofrer estigmas devidos à sua identidade ou expressão de gênero. Além disto, ainda há o fato de que, ao participarem de pesquisas científicas, elas correm o risco de serem expostas a situações inadequadas, constrangedoras ou mesmo antiéticas.

As entrevistas abordaram questões relacionadas a identidade de gênero, expressão social do gênero, tratamentos de saúde realizados no processo de transição, percepção e funcionamento da própria voz, e influência desses aspectos nas interações sociais.

O processo de análise das entrevistas em interação com as percepções dos pesquisadores no campo possibilitou o surgimento de categorias analíticas, que foram aflorando ao longo do estudo. As categorias analíticas, seus elementos e reflexões, serão apresentados na sequência.

A necessidade de reflexão quanto a essas categorias se dá pela riqueza gerada a partir da compreensão dos aspectos discutidos, por parte dos pesquisadores e profissionais de saúde - em especial, em fonoaudiologia e em saúde coletiva. Principalmente porque, na formação universitária em fonoaudiologia, até então, tem-se pouco ou nenhum contato com as questões de gênero, e especialmente porque se percebe que o presente objeto de estudo, a comunicação humana, é fortemente influenciada e está implicitamente relacionada às questões sociais de gênero.

\section{Conforto e segurança quanto à expressão social de gênero}

O corpo tem muito significado quando se fala de expressão de gênero de pessoas transexuais. O uso do binder, de bonés, de roupas mais largas e as modificações corporais (como o uso da barba e a realização da cirurgia de mamoplastia) estão para além de necessidades individuais ${ }^{20}$, representando modos de ser e de agir desenvolvidos pelos homens trans entrevistados, para que sua expressão social de gênero esteja de acordo com o gênero com o qual se identificam.

Esse corpo te coloca no mundo, esse corpo que vai definir o que você pode e o que você não pode [...] o corpo tem uma materialidade assim, tanto que eu acho muito interessante quando você fala sobre voz $[\ldots] .(\mathrm{T})$

Pode-se considerar que as singularidades, as formas utilizadas para a expressão do gênero, são também recursos de comunicação na adequação do corpo às expectativas sociais, e estes recursos devem ser levados em consideração e contextualizados quando se discutem os aspectos 
fisiológicos e comportamentais do funcionamento da voz e da comunicação dos homens trans em suas interações sociais 9 .

\section{Importância da voz}

A relevância da voz na percepção dos homens trans entrevistados aparece de duas maneiras distintas. A princípio, a voz pode não gerar nenhum tipo de expectativa ou desconforto em relação à expressão de gênero, como no caso em que um dos entrevistados relata que, mesmo tendo expressado certa dificuldade nas interações sociais em momentos anteriores de sua vida, a voz não gera (ou gerava) nenhum tipo de anseio específico.

Sempre vivi meio no intermédio: não era muito menino nem era muito menina. Eu me camuflava ali para poder passar despercebido. (L)

Mas, em relação ao entrevistado acima, talvez pelo fato de não buscar uma expressão de gênero de acordo com os padrões binários utilizados, a voz não pareça ser um aspecto relevante em sua comunicação.

Diferente relevância é dada à voz por outros entrevistados, para os quais o tema aparece como um fator marcante da expressão de gênero, influenciando, de maneiras diversas, relacionamentos interpessoais e até a vida profissional. No sentido de que, quando a voz está confortável com a expressão de gênero, as situações sociais de falar com ou para outras pessoas se torna uma prática sem dificuldades ou complexidade. Uma vez que a conformidade entre o que se expressa e o que o interlocutor lê não gera nenhum tipo de desconforto, não havendo estranhamento no outro quanto ao gênero de quem fala, esta conformidade entre o que se expressa e o que é lido socialmente tem especial importância, no sentido de não constranger, expor ou colocar em situação de vulnerabilidade os homens trans, nas mais diversas situações de interação social.

\footnotetext{
Assim, o lance da voz também é muito importante, porque, da mesma forma que você anda curvado e usa uma faixa para esconder seus intrusos, você também acaba optando por fazer uma voz mais grossa, para que as pessoas não venham perceber [...] eu faço uma voz mais grossa quando eu vou me comunicar com as pessoas. $(\mathrm{K})$
}

Percebe-se, na fala acima, o uso da voz em sua dimensão mais subjetiva, não apenas no aspecto orgânico e fisiológico de uma voz de frequência grave, mas para além do aspecto material do corpo, expressando um conjunto e refletindo a subjetividade do falante em interação com um ouvinte; podendo ser transformada e adaptada de acordo com processo de interação e comunicação através do qual a pessoa se expressa, passível de ser vista como um elemento que contribui para a performatividade de gênero ${ }^{16}$, sendo trabalhada de maneira que propicie uma comunicação que represente a subjetividade do falante, adaptável aos contextos de comunicação, possibilitando uma comunicação efetiva e, mais do que isto, uma comunicação segura.

ISSN 1982-8829 Tempus, actas de saúde colet, Brasília, 11(4), 09-24, dez, 2017. Epub Ago/2018 
Utilizar essa noção de performatividade contribui com a maneira de perceber que a produção do gênero vocal se dá na interação entre as pessoas, na qual as trocas entre os falantes influenciam as maneiras de expressão do gênero vocal, como mostrado por Azul',13, em seu 'modelo de produção do gênero vocal em interação', que descreve que, na interação, os fatores que contribuem para esta produção compreendem: 1. Identidade de gênero (posição subjetiva de gênero); 2. Desejo de atribuição de gênero; 3. Expressão social de gênero (apresentação de gênero); e 4. Atribuição de gênero dada à voz pela própria pessoa e pelas outras pessoas. Assim, trabalhar a voz de cada homem trans de acordo com seu contexto pessoal e social, considerando suas interações sociais, possibilita que a voz corporificada nessas relações seja compreendida em suas variadas dimensões e não se torne uma barreira de comunicação, explorando todas as potencialidades que possam ser desenvolvidas.

A voz, quando não representa o gênero com o qual o falante se identifica, pode gerar desconforto em determinadas interações sociais. Este desconforto, ao se repetir, faz com que a pessoa que o sente busque se defender, evitando, assim, se comunicar em situações que possam expô-la. Deste modo, a não conformidade da voz com a expressão de gênero pode constituir uma barreira de acesso ou de comunicação de um homem trans, o que pode influenciar outros níveis de sua vida social, como os estudos ou o trabalho.

[...] e a minha voz, pra mim, é uma vergonha, porque eu acho ela muito fina, e isso, muitas vezes, me empata de falar em público, porque a minha voz, ela não me representa. Então, eu sei que isso é uma característica pra já me olharem diferente. Para mim, isso me incomoda muito. (Z)

Pra mim, a minha voz deveria ser mais grossa, porque uma voz entrega a gente [...] a voz, para mim, é tudo. Se eu não tenho uma boa voz para falar, uma voz que me representa, assim, eu fico desconfortável de conversar com as pessoas, me sinto mal [...] porque se eu falar fino, vai me entregar, vai vim aquela voz fina [...] eu não me sinto bem, fico desconfortável, abaixo a cabeça, já não sai mais nem a fala mais... É isso que acontece comigo, eu me travo todinho. (Q)

\section{Voz e Hormonioterapia}

O tratamento com o hormônio testosterona, realizado pelos homens trans que optam por este tipo de terapia, promove diversos efeitos na fisiologia e na função vocal, de acordo com as variações corporais individuais e relacionadas às especificidades dos tratamentos, como o tipo de testosterona, a via de administração e o tempo de hormonioterapia ${ }^{15}$.

Nem todos os entrevistados já haviam realizado ou estavam realizando hormonioterapia, mas, mesmo assim, já cultivavam expectativas quanto à mudança para uma voz mais grave, que possibilitasse situações de interação mais confortáveis com outras pessoas, no sentido de que não gerassem constrangimentos; que seus interlocutores não os lessem socialmente com o gênero inadequado ou fizessem perguntas quanto à sua identidade de gênero. 
Porque, como eu ainda não faço a hormonioterapia, eu faço isso. E, por já não ter a voz tão feminina, me ajuda bastante. Eu não tenho disforia, mas, da mesma forma, eu ainda uso essa técnica pra poder ficar com uma voz mais grossa. Pra que as pessoas possam ter mais facilidade de me reconhecer como eu realmente sou. $(\mathrm{Z})$

O efeito mais esperado da hormonioterapia relacionado à voz é a diminuição da frequência fundamental, que se dá quando a voz fica mais grave, caracterizando uma voz mais masculina. É sabido que grande parte dos homens trans que fazem este tipo de tratamento desenvolvem uma mudança vocal ${ }^{21}$.

É engraçado falar essa questão da voz... O que eu mais queria, em questão dos hormônios, é a voz, porque o que mais me incomoda é a voz, porque ela é fina [...]. (J)

O entrevistado acima ainda descreve uma situação de trabalho na qual foi preciso usar muito o telefone e as pessoas que ligavam, sabendo que iam falar com alguém do gênero masculino, por causa do seu nome, ao telefone, não o reconheciam quando ele se apresentava.

[...] eu dei meu telefone, e todas as pessoas ligaram: “Ai... mas não era um menino?”. "É um menino".

E as pessoas nunca aceitaram [...] e aí, foi um tempo que me causou muita disforia com a minha voz. (J)

Os efeitos de uma voz mais conforme às características sociais de gênero proporcionam situações de comunicação mais confortáveis, aumentando o bem-estar dos falantes.

Os resultados da hormonioterapia na qualidade da voz atualmente conhecidos na literatura científica $^{15}$ são satisfatórios no sentido de modificar a frequência fundamental da voz, tornando seu tom mais grave. Corroborando a literatura, eis a fala abaixo, cujo sujeito sentiu rapidamente os efeitos da testosterona em sua voz:

Testosterona tem o impacto muito forte, diferente das meninas que usam estrógeno, que é um hormônio muito mais fraco em relação à testosterona. Então, pra elas demoram; pr'a gente, é rápido assim. A voz foi rápido mesmo. (T)

No entanto, na perspectiva de outros homens trans, que também foram ouvidos e já realizaram ou realizam a hormonioterapia, nem todos consideram que a modificação para uma voz mais masculina foi satisfatória. Isto mostra que as mudanças não são tão nítidas ou efetivas, e/ou que a própria pessoa pode não ficar satisfeita com o nível de sua nova qualidade vocal ${ }^{15}$.

É importante ressaltar que a qualidade de uma voz 'mais masculina' descrita neste trabalho deve ser considerada sob a perspectiva da própria pessoa, de acordo com o seu conforto em relação à sua expressão de gênero, e não restrita a uma perspectiva técnica de uma avaliação feita a partir do

ISSN 1982-8829 Tempus, actas de saúde colet, Brasília, 11(4), 09-24, dez, 2017. Epub Ago/2018 
parâmetro profissionais da área da voz.

As diferentes percepções de voz ilustram os homens que sentem que a testosterona transforma a voz de forma efetiva, em diálogo com os que relatam que a voz não apresenta tanta mudança, não fica tão grave, com a hormonioterapia. Como no caso do entrevistado abaixo, que, mesmo após meses de tratamento, ainda não percebia sua voz como sua, apesar de as pessoas perceberem uma voz mais grave.

Então, antes da hormonioterapia, eu sempre tive problemas em falar; tive até problemas em pronunciar, fazer determinadas pronúncias, porque eu não gostava da minha voz, não suportava a minha voz, tinha dificuldade de pronunciar determinadas palavras. Eu tropeçava porque eu queria falar rápido pra ninguém ouvir; aí, tropeçava, falava errado uma série de coisas; aí, eu evitava falar muito [...] hoje, eu escuto a minha voz... Aí, eu vejo realmente quanto minha voz mudou, né? Então, isso me deixa feliz. (K)

\section{Autopercepção vocal x percepção do ouvinte}

As diferentes percepções sobre a voz estão relacionadas à autopercepção vocal e à percepção do ouvinte. Quanto à autopercepção, geralmente, no início da hormonioterapia, os homens não percebem tanta modificação em suas vozes; os seus interlocutores mais próximos, como amigos ou familiares, costumam perceber primeiro. $\mathrm{O}$ fato de as pessoas perceberem uma voz mais masculina é visto como positivo, fazendo com que os homens até se comuniquem e interajam mais.

E nos meus dois relacionamentos, a minha atual, ela diz que a minha voz é ótima - mas é horrível, né? - tudo bem. Já minha ex, ela dizia que tinha horas que eu conseguia falar mais grosso. Aí, eu dizia: 'É, mas pra eu falar mais grosso, eu tenho que controlar mais a respiração, eu tenho que articular'. E pra fazer isso toda hora, não dá. É cansativo. (Z)

[...] às vezes, eu evito cantar em casa, porque ouvir a minha própria voz me incomoda, eu acho ainda muito feminina. Por isso que eu gosto tanto de tá rouco, porque quando eu tô rouco, a voz tá mais grossa. No trabalho, eu comentando com o pessoal: 'Ah, eu gosto de quando eu tô gripado porque a voz fica mais grossa'. Aí, elas olharam pra mim: 'Não, a tua voz tá do mesmo jeito'. 'Mas, pra mim, eu ouvindo, ela tá diferente'. Então, isso chega me deixa mais tagarela. $(Z)$

Outros momentos em que os homens começam a perceber suas modificações na voz se dão na interação com interlocutores alheios ao seu ciclo cotidiano, quando, por exemplo, falam com um desconhecido e este imediatamente o identifica de acordo com o gênero masculino.

A Durateston, em um mês, eu consegui isso [falando sobre a barba ter crescido] [...] eu sou uma pessoa passável, você entra num local - mas eu percebo que não é só pela minha barba -, eu percebo que a minha voz também, minha voz me dá esse lance de que eu consigo chegar em determinado local e não ser identificado. Eu não tenho nenhum problema em ser identificado como trans, mas eu não quero ser identificado o contrário. Então, aí, eu percebo que são os dois fatores na minha vida, hoje em dia, que 
têm me deixado extremamente bem, que é a minha barba e a minha voz. Porque, assim, justamente são eles que estão fortalecendo o meu corpo como eu quero, como eu sou realmente, e ser entendido assim. $(\mathrm{K})$

É importante, então, ressaltar a relevância de outros elementos corporais e comunicacionais, como o uso da barba na composição com a voz, contribuindo, assim, para a passabilidade.

\section{Relações entre voz, saúde e interações sociais}

Este trabalho propõe, a partir da inter-relação entre corpo, subjetividade e saúde coletiva ${ }^{4,20}$, uma reflexão sobre como a voz e a comunicação nas interações sociais se relacionam com a discursividade de gênero ${ }^{16}$; como esta expressão é transformada e transformadora das interações sociais e como esta relação é percebida pelos homens trans envolvidos no estudo.

As diferentes percepções que afloram no estudo permitem a compreensão da existência de diferentes fatores que contribuem para a expressão do gênero vocal dos homens trans, e de que há uma diversidade entre os indivíduos, na qual há, sim, desejos e necessidades comuns, mas muitas particularidades e individualidades.

Alguns homens, mesmo em hormonioterapia, não estão satisfeitos com sua produção vocal. Daí, a importância da reflexão a respeito de relação entre a voz e as interações sociais. Por exemplo: um homem trans pode passar por situações sociais em seu gênero, em que seja lido de maneira equivocada, em decorrência da sua voz ou de outro aspecto da sua comunicação, uma vez que a expressão de gênero carrega características subjetivas, que se interligam com a materialidade através da corporalidade e, muitas vezes, pode não se enquadrar nos padrões normativos sociais de um homem cisgênero heterossexual.

Essa reflexão quanto aos estereótipos de gênero de masculinidade, relacionada muitas vezes a comportamentos de comunicação machistas, foi trazida de maneira expressiva na fala do entrevistado abaixo:

Outra questão que tem também - isso é subjetividade, mas tudo bem - que a cultura ensina, a cultura traz dois ensinamentos pr'a gente: primeiro, ela diz que, para ser homem tem que ter a voz grossa. A cultura fez esse ensinamento pr'a gente durante muito tempo. Chegou num momento que essa cultura também adquiriu, fez outro ensinamento, né? 'Voz grossa é voz de macho, é voz de homem machista'. Então, são dois ensinamentos que nós trazemos dentro da cultura, ou seja, eu querer ter a voz grossa tá indo de encontro com o que essa cultura diz, mas tá indo ao meu favor, porque isso também alimenta a minha masculinidade. Agora, também eu tenho um certo receio de um determinado local falar grosso e forte, e a pessoa entender que eu sou um homem machista, grosso. 'Olha aí, já fala desse jeito para dizer que é o rei' [...] e não é nada disso, entendeu? (M)

Essa percepção convida à problematização da "obrigatoriedade" que a normatização gera, de

ISSN 1982-8829 Tempus, actas de saúde colet, Brasília, 11(4), 09-24, dez, 2017. Epub Ago/2018 
seguir padrões socialmente impostos dos estereótipos de gênero, no sentido de que a expressão de gênero infligida pela sociedade impõe os estereótipos de traços femininos ou masculinos e, consequentemente, a expressão de voz e modos de falar 'necessitam' estar enquadrados nestes parâmetros sociais.

No processo de transição, há muitas pessoas que se encontram insatisfeitas por não atingirem determinados padrões sociais impostos - de masculinidade, por exemplo -, padrões estes segundo os quais todos os homens trans devem estar de acordo com um modelo de masculinidade - voz e jeito masculino - que legitime sua identidade de gênero em suas interações sociais.

Essa problematização contribui para a noção de que a busca por uma voz ideal, caso exista, deve se dar no sentido da busca de uma expressão de gênero que reflita a subjetividade de quem se identifica com ela ${ }^{22}$. E não na busca de um padrão socialmente imposto, o qual muitas vezes cria expectativas distantes de serem alcançadas, podendo gerar desconforto e sentimentos de inadequação aos falantes.

Não se pretende, aqui, argumentar que a busca por uma voz ou expressão de gênero que determinada pessoa almeje não seja legítima, mas discorrer e refletir sobre a busca de uma expressão por meio de uma voz que seja pessoalmente e socialmente confortável e segura.

\section{Suporte de profissional da voz}

O aprimoramento da função vocal de homens trans com o auxílio de um profissional da fonoaudiologia já é descrito na literatura, apesar de os estudos ainda serem escassos ${ }^{17}$. Entre os estudos disponíveis que abordam a atuação do fonoaudiólogo com homens trans, há diferentes tipos de abordagens e focos de atenção. Alguns recomendam tratamento para disfonias por tensão muscular, com especial atenção ao aumento gradual das doses do tratamento hormonal, estimulando uma adequada respiração diafragmática associada a exercícios de execução suave e determinados ajustes vocais ${ }^{23,24}$. Outros focam em informações sobre higiene vocal e recomendações para a prevenção da fadiga vocal ${ }^{21}$.

Há, portanto, a necessidade do desenvolvimento de pesquisas relacionadas à função vocal de homens trans ${ }^{13}$, inclusive, no contexto brasileiro ${ }^{12}$, onde, até o momento em que este trabalho foi escrito, não havia pesquisas publicadas. Porém, independentemente das temáticas ou abordagens técnicas já desenvolvidas nas pesquisas, deve-se refletir a respeito do desenvolvimento de melhores práticas éticas e clínicas na atenção à saúde das pessoas trans, o que já contribuiria para a redução das vulnerabilidades às quais estas pessoas estão expostas nos cuidados em saúde.

Nesse ponto, se inserem também os profissionais da fonoaudiologia, que, ao trabalhar voz e comunicação, estão intervindo diretamente na qualidade de vida dessas pessoas ${ }^{7}$. Não bastando conhecer e utilizar métodos que mensurem qualidade de vida relacionada à saúde, é preciso respeitar e estar sensível à diversidade de gêneros e às individualidades, bem como compartilhar, nos mais 


\section{$21 / /$}

diversos espaços - especialmente, entre os demais profissionais -, as questões relacionadas à saúde e à qualidade de vida das pessoas trans.

Desse modo, há a necessidade de os profissionais da saúde aumentarem e qualificarem o conhecimento sobre a saúde das pessoas transexuais e melhorar a sensibilidade, o respeito, e as atitudes essenciais para o fornecimento de cuidados adequados a este público ${ }^{7}$.

\section{Processo Transexualizador, Fonoaudiologia e Saúde Coletiva}

Em relação à Portaria $n^{0}$ 2.803, de 19 de novembro de 2013, que aborda o Processo Transexualizador no Sistema Único de Saúde (SUS) ${ }^{25}$ - reconhecidamente um marco no acesso à saúde e aos procedimentos relacionados ao processo de transição de gênero -, cabe uma reflexão sobre o que ela define enquanto procedimentos relacionados à voz, pois enumera apenas um procedimento hospitalar (embora de alta complexidade): a cirurgia de tireoplastia. No entanto, tal cirurgia tem somente o objetivo de feminizar a voz e/ou alongar as pregas vocais no processo transexualizador, não se aplicando, portanto, às demais necessidades dos homens trans.

É sabido que, no SUS, a maioria dos ambulatórios de saúde trans possui o profissional fonoaudiólogo na equipe multidisciplinar ${ }^{20}$, entretanto, o fato de este profissional não estar inserido obrigatoriamente na portaria supracitada faz com ele não ganhe força política de ação nessa área e não seja cotado como um profissional essencial para atender a tal população.

Estar citado na portaria até possibilita visibilidade ao fonoaudiólogo na atenção à saúde das pessoas trans, no âmbito da saúde coletiva brasileira, uma vez que se almeja que este tipo de atendimento não necessariamente esteja apenas vinculado aos centros de referência do processo transexualizador, mas sua presença deve se estender a todos os serviços ambulatoriais da fonoaudiologia no SUS. Inclusive, promovendo a disseminação da temática e de abordagens adequadas dessa área para os profissionais e estudantes de fonoaudiologia que ainda não tenham familiaridade com o tema ${ }^{3,26}$. Há, assim, a necessidade e a demanda de verdadeiramente ser incluído o profissional da fonoaudiologia na portaria supracitada.

\section{CONSIDERAÇÕES}

As percepções sobre voz e interações sociais compartilhadas pelos atores deste estudo demonstram possibilidades de reflexão sobre como a voz e, consequentemente, a comunicação podem influenciar o bem-estar de um homem trans em sua vida pessoal e social. O que representa um convite a uma modificação no modo de enxergar e reagir a determinados padrões culturais, que já são tão naturais aos olhos da sociedade brasileira.

A discussão de uma abordagem em saúde integral na atenção à saúde das pessoas trans no SUS busca superar as normatividades sociais, no sentido de desconstruir preconceitos e crenças, que muitas vezes nas interações sociais colocam as pessoas trans em situação de vulnerabilidade, 
inclusive em saúde.

No tocante à saúde coletiva, tal ponderação se reflete nas atitudes e abordagens que podem ser transformadas e implementadas para a promoção da saúde integral das pessoas trans. Especialmente, quanto à preparação técnica e cultural, com uma abordagem adequada, perpassando desde o uso adequado da linguagem, às questões de gênero, até chegar às abordagens em atenção à saúde. Sempre atentando para os padrões que são pregados e que não devem ser reproduzidos ou impostos, buscando seguir protocolos de orientações técnicas e de boas práticas já disponíveis na literatura ${ }^{3,23}$. Com respeito às diversidades e às individualidades, considerando preferências e trabalhando possibilidades, diferentemente de buscando um padrão social a ser alcançado, mas objetivando uma expressão vocal e comunicativa que seja confortável, fisicamente e socialmente. Isto porque, ainda que os limites existam para qualquer pessoa, a comunicação é uma habilidade que pode ser desenvolvida e aprimorada, juntamente com outros recursos que possibilitem adequar a expressão de gênero à maneira como cada pessoa se identifica. Vale, portanto, ressaltar que considerar a terapia fonoaudiológica com uma abordagem adequada e crítica quanto às questões sociais e subjetivas relacionadas à expressão de gênero, além dos aspectos subjetivos da própria comunicação e da voz, representa um grande potencial à promoção da saúde das pessoas trans.

Cabe dizer, ainda, que a literatura sobre voz utilizada para a construção e a discussão deste estudo é, em sua maioria, constituída por estudos internacionais e, portanto, baseada em falantes transgêneros de outras nacionalidades. As evidências científicas brasileiras sobre a saúde dos homens trans ainda são escassas e há a necessidade do desenvolvimento de estudos que tragam à luz a perspectiva das próprias pessoas interessadas para a construção de intervenção terapêutica voltada para peculiaridades que dialoguem com os aspectos sociais e culturais envolvidos na expressão de gênero, na sociedade brasileira.

Tudo isso no sentido de buscar a percepção de que a atenção à saúde da pessoa trans deve refletir que as interações sociais se dão nas mais diversas situações de comunicação e são influenciadas pelas possibilidades ou barreiras de expressão que afetam relacionamentos pessoais e sociais.

\section{REFERÊNCIAS}

1. Brasil, Ministério da Saúde, Secretaria de Gestão Estratégica e Participativa, Departamento de Apoio à Gestão Participativa. Política Nacional de Saúde Integral de Lésbicas, Gays, Bissexuais, Travestis e Transexuais. Brasília: Ministério da Saúde. 2012.

2. Mello L, Perilo M, Braz CA, Pedrosa C. Políticas de saúde para lésbicas, gays, bissexuais, travestis e transexuais no Brasil: em busca de universalidade, integralidade e equidade.

Sexualidad, Salud y Sociedad. 2011 Dec; (9):7-28.

3. Coleman E, Bockting W, Botzer M, Cohen-Kettenis P, DeCuypere G, Feldman J et al. Standards of Care for the Health of Transsexual, Transgender, and Gender-Nonconforming 
People. International Journal of Transgenderism. 2012 July; 13(4):165-232.

4. Aran. M, Zaidhaft S, Murta D. Transexualidade: corpo, subjetividade e saúde coletiva. Psicologia \& Sociedade. 2008; 20(1):70-79.

5. Neumann K, Welzel C, Berghaus A. Operative voice pitch raising in male-to-female transsexuals. Eur. J. Plast. Surg. 2002; (25):209-214.

6. Owen K, Hancock AB. The role of self and listener perceptions of femininity in voice therapy. Int. J. Transgender. 2010; (12):272-284.

7. Hancock AB, Haskin G. Speech-Language Pathologists' Knowledge and Attitudes Regarding Lesbian, Gay, Bisexual, Transgender, and Queer (LGBTQ) Populations. American Journal of Speech-Language Pathology 2015 May; 24, 206-221.

8. Azul D. Transmasculine people's vocal situations: a critical review of gender-related discourses and empirical data. Int. J. Lang. Commun. Disord. 2015 Jan; 50(1):31-47.

9. Azul D. Gender-related aspects of transmasculine people's vocal situations: insights from a qualitative content analysis of interview transcripts. Int. J. Lang. Commun. Disord. 2016 Nov; 51(6):672-684.

10. Gelfer MP, Schofield KJ. Comparison of acoustic and perceptual measures of voice in MtF transsexuals perceived as female versus those perceived as males. J. Voice. 2000; 14(1):22-33.

11. Davies S, Goldberg JM. Clinical aspects of transgender speech feminization and masculization. Int. J. Transgenderism. 2006; (9):3-4, 167-196.

12. Lanz L. O corpo da roupa: a pessoa transgênera entre a transgressão e a conformidade com as normas de gênero. Uma introdução aos estudos transgêneros. Curitiba: Transgente. 2015, 456.

13. Azul D. Transmasculine people's vocal situations: a critical review of gender-related discourses and empirical data. Int. J. Lang. Commun. Disord. 2015 Jan; 50(1):31-47.

14. Scheidt D, Kob M, Willmes K, Neuschaefer-Rube C. Do we need voice therapy for female-to-male transgenders? In Murdoch, BE et al. Eds. 2004 IALP-Congress Proceedings. Brisbane: Speech Pathology Australia.

15. Azul D, Nygren U, Södersten M, Neuschaefer-Rube C. Transmasculine People's Voice Function: A Review of the Currently Available Evidence. J. Voice. 2017 Mar; 31(2):261.e9-261. e23.

16. Butler J. Corpos que pesam: sobre os limites discursivos do 'sexo'. In: Louro, GL (Org.).

ISSN 1982-8829 Tempus, actas de saúde colet, Brasília, 11(4), 09-24, dez, 2017. Epub Ago/2018 
O corpo educado: pedagogias da sexualidade. Trad. Tomaz Tadeu da Silva. Belo Horizonte: Autêntica, 1999, 151-172.

17. Minayo, MCS. O desafio do conhecimento: pesquisa qualitativa em saúde. São Paulo: Hucitec. 2010, 407.

18. Noy C. Sampling Knowledge: The Hermeneutics of Snowball Sampling in Qualitative Research. International Journal of Social Research Methodology. 2008 Oct;11(4):327-344.

19. Vinuto J. A amostragem bola de neve na pesquisa qualitativa: um debate em aberto. Temáticas, Campinas. 2014; 22(44):203-220.

20. Brasil. Ministério da Saúde, Secretaria de Gestão Estratégica e Participativa, Departamento de Apoio à Gestão Participativa. Transexualidade e Travestilidade na Saúde. Brasília: Ministério da Saúde, 2015. 194.

21. Nygren U, Nordenskjöld A, Arver S, Södersten M. Effects on voice fundamental frequency and satisfaction with voice in trans men during testosterone treatment: a longitudinal study. J. Voice. 2016 Nov;30(6):766.e23-766.e34.

22. Davies S, Papp VG, Antoni C. Voice and communication change for gender nonconforming individuals: giving voice to the person inside. Int. J. Transgend. 2015;16:117-159.

23. Adler RK, Constansis AN, Van Borsel J. Female-to-male transgender/transsexual considerations. In: Adler RK, Hirsch S, Mordaunt M. Eds. Voice and Communication Therapy for the Transgender/Transsexual Client: A Comprehensive Clinical Guide. San Diego: Plural Publishing; 2012:153-185.

24. Cosyns M, Van Borsel J, Wierckx K, Dedecker D, Van de Peer F, Daelman T et al. Voice in female-to-male transsexual persons after long-term androgen therapy. Laryngoscope. 2014 Jun;124(6):1409-1414.

25. Brasil. Ministério da Saúde. Portaria n 2.803, de 19 de novembro de 2013. Redefine e amplia o Processo Transexualizador no Sistema Único de Saúde (SUS). Brasília: Ministério da Saúde. 2013.

26. Thornton J. Working with the transgender voice: the role of the speech and language therapist. Sexologies. 2008;17:271-276.

Artigo apresentado em 20/07/17

Artigo aprovado em 21/03/18

Artigo publicado no sistema em 31/08/18 